\section{Anseth leads MRS Board of Directors for 2016}

www.mrs.org/board
Progress in Materials Science, and Biotechnology and Bioengineering, as well as on the Board of Governors for Acta Materialia, Inc. She serves on the Advisory Council for the National Institute for Biomedical Imaging and Bioengineering of the NIH and is the chair of the US NAE Frontiers of Engineering Program. Anseth has been an organizer of MRS symposia, presided as a meeting chair for the 2009 MRS Fall Meeting, and was elected to the MRS Board of Directors in 2003, where she also served as chair of the Strategic Planning Committee. She has been recognized with the MRS Outstanding Young Investigator Award (2001) and the inaugural Mid-Career Researcher Award (2012).

\section{Susan Trolier-McKinstry Vice President/President-Elect}

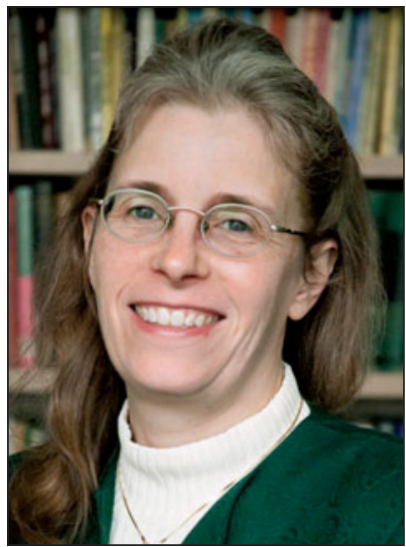

and her $\mathrm{PhD}$ degree from the University of Colorado in 1994. She then conducted postdoctoral research at the Massachusetts Institute of Technology as a National Institutes of Health (NIH) Fellow and subsequently joined the Department of Chemical and Biological Engineering at the University of Colorado Boulder as an assistant professor in 1996. Her research interests lie at the interface between biology and engineering, where she designs new biomaterials for applications in drug delivery and regenerative medicine. She is an elected member of the US National Academy of Engineering (NAE) (2009), the Institute of Medicine (2009), and the National Academy of Sciences (2013). She is also a Fellow of the American Association for the Advancement of Science, the American Institute for Medical and Biological Engineering, and MRS. Anseth serves as an associate editor for Biomacromolecules,
Susan Trolier-McKinstry is a professor of ceramic science and engineering and professor of electrical engineering at The Pennsylvania State University (Penn State). She is also director of the nanofabrication facility and co-director of the Center for Dielectric and Piezoelectric Studies. She received her $\mathrm{PhD}$ degree in ceramic science from Penn State in 1992 , and has been a member of the faculty since then. She greatly enjoys working with students and has mentored over 50 graduate students. Her research group has authored more than 350 papers and has numerous patents. Group research spans from probing the fundamental mechanisms that contribute to the dielectric and piezoelectric properties of thin films, to processing studies on the deposition and patterning of complex oxides, to integration of functional films into

Weidenkaff, University of Stuttgart. 
microelectromechanical systems. She is an associate editor of Applied Physics Letters; a Fellow of MRS, IEEE, and The American Ceramic Society; and an academician in the World Academy of Ceramics. She has previously served as the president of the IEEE Ultrasonics, Ferroelectrics, and Frequency Control Society, as well as Keramos and the Ceramic Education Council. TrolierMcKinstry has actively participated in MRS since graduate school. She has organized numerous symposia, and was a Meeting co-chair for the 2003 MRS Fall Meeting. Subsequently, she served on the Program Development Subcommittee until serving a term on the MRS Board of Directors. At that point, she served as the chair of the Strategic Planning Committee.

\section{Oliver Kraft}

Immediate Past President

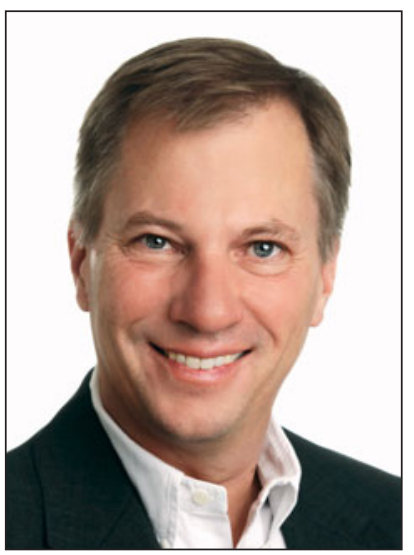

Oliver Kraft is Director at the Institute for Applied Materials and jointly Robert Bosch Professor for Nanostructured Functional Materials at the Karlsruhe Institute of Technology (KIT) in Germany. Since 2011, Kraft is also speaker of the Helmholtz Program: Science and Technology of Nanosystems. His research interests focus on studying deformation and degradation mechanisms in nanomaterials for a wide range of applications, from microelectromechanical systems and microelectronics to energy conversion and storage. Kraft graduated from the University of Stuttgart in 1995 with a degree in physical metallurgy. From 1996 to 1997 , he was a postdoc at Stanford University. He also worked as a research scientist at the Max-Planck-Institut für
Metallforschung in Stuttgart from 1997 to 2002. He has authored or co-authored more than 200 articles. Kraft is active in several national and international materials science societies. He has co-organized more than 20 international symposia and meetings and is currently one of the coordinators of the committee for Functional Materials of the German Materials Research Society (DGM). Since 2008, he is one of the elected referees for the DFG (German Research Foundation) in the area of materials science and engineering. For MRS, he served as Meeting chair for the 2005 MRS Spring Meeting and has been a member of the Board of Directors since 2011. In 2014, Kraft served as MRS vice president/president-elect.

\section{Sean J. Hearne}

Secretary

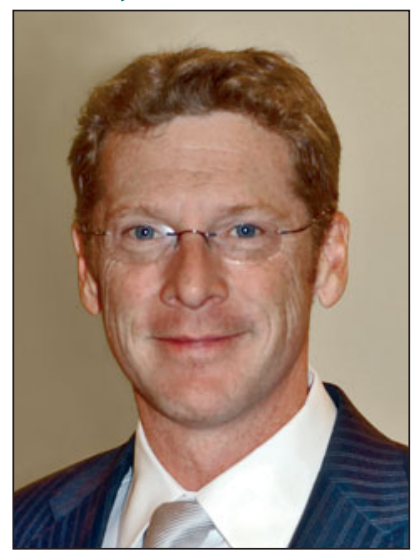

Sean J. Hearne is currently Science Staff Manager in the US Department of Energy's Center for Integrated Nanotechnologies located at Sandia National Laboratories. He received his $\mathrm{PhD}$ degree in solid-state physics from Arizona State University in 2000. He worked from 2000 to 2001 at Intel Corporation, where he was a senior process engineer in the Components Research Group in Hillsboro, Ore. Since 2001, Hearne has worked at Sandia National Laboratories. His research has primarily focused on the sources of intrinsic stress creation and evolution during thinfilm deposition, and is well cited in the area of metal-organic chemical vapor deposition growth of $\mathrm{GaN}$, and in the fundamental mechanisms inducing stress during Volmer-Weber thin-film growth. This work led him into other research topics, including micro- and nanofabrication and nano-enabled devices for electrical energy storage. Hearne's current interests focus on enabling new programs to develop novel in situ techniques for the study of high energy and power density systems. He has been active in the MRS community since attending his first MRS Meeting in 1995 as a graduate student. Over the years, he has presented, organized symposia, and served on a number of committees and task forces, and he has chaired the former MRS Information Services Committee, which oversees all of the MRS print and online publications, including MRS Bulletin, Journal of Materials Research, and the MRS Symposium Proceedings.

\section{David J. Parrillo Treasurer}

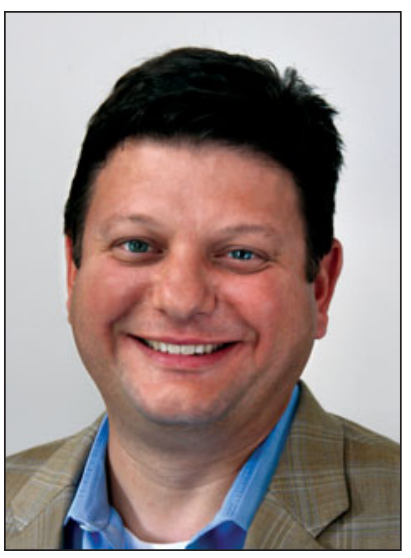

David J. Parrillo is the Global Research and Development Director of Packaging and Specialty Plastics for The Dow Chemical Company working to evolve Dow's strategy in the lithium-ion battery market. He holds a BS degree in chemical engineering from the University of Rhode Island and a $\mathrm{PhD}$ degree in chemical engineering from the University of Pennsylvania. He has 20 years of experience in chemical engineering, application development, and technology commercialization. Prior to joining Dow in 2007, he held positions at General Electric and Air Products and Chemicals. Parrillo is a member of the External Advisory Board at the University of California-Santa Barbara for Chemical Engineering and the Board of Directors of the West Midland Family Center. He holds 13 US patents. He received the Whitney 
Technical Achievement Award in 2000 from GE Plastics and the Technology Innovation Award in 1998 from Air Products and Chemicals. He selected and developed The Dow POWERHOUSE Solar Shingle team, which went on to receive numerous awards: the 2009 Time Magazine Best 50 Inventions, the 2010 Globe Award, the 2010 Environmental Excellence In Emerging Technology, the 2012 Edison Award for Global Best New Product, and the 2012 Popular Mechanics Breakthrough Award. He served as a 2014 MRS Spring Meeting chair and was a featured speaker at both the 2010 and 2011 MRS Technology Innovation Forums.

\section{Todd M. Osman}

\section{Executive Director}

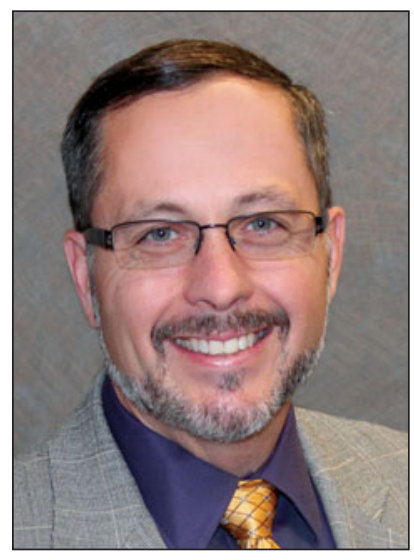

Todd M. Osman became Executive Director of MRS in September 2008. During his tenure, MRS has launched the Materials Research Society Foundation, expanded its communications and meetings portfolio, and broadened its outreach and engagement programs. Prior to joining MRS, Osman co-founded The Pennsylvania NanoMaterials Commercialization Center. He also spent 11 years at United States Steel Corporation, where he received peer and corporate recognition for his research and coordinated cooperative R\&D programs in North America, Europe, and Asia. He received his $\mathrm{PhD}$ degree in materials science and engineering from Case Western Reserve University and has authored numerous articles. Osman is a member of the Board of Directors of the Lighthouse Foundation, a nonprofit charitable organization, and a member of the MRS Board of Directors.

\section{Board of Directors}

\section{Charles T. Black (2017)}

Black is a scientist and the group leader for electronic nanomaterials in the Center for Functional Nanomaterials, a US Department of Energy User Facility at Brookhaven National Laboratory. He manages a group of 10 scientists exploring the use of nanostructures for solar energy conversion. His research interests include using nanostructured materials and self-assembly approaches to improve the performance of solar devices. His involvement with MRS started in 1997, and he was a 2013 MRS Fall Meeting co-chair.

\section{Alexandra Boltasseva (2016)}

Boltasseva is currently an associate professor in the School of Electrical and Computer Engineering and Birck Nanotechnology Center at Purdue University. She specializes in nanophotonics and nanotechnology focusing on optical metamaterials, nanoscale optics, plasmonics and plasmonic materials, nanofabrication, and material growth. Boltasseva has been a member of MRS since 2005, featuring six MRS Meetings' presentations, including three invited talks, the 2013 MRS Outstanding Young Investigator lecture, and two invited contributions to MRS Bulletin.

\section{Jeffrey Brinker (2016)}

Brinker is currently the Distinguished and Regent's Professor of Chemical and Biological Engineering and Molecular Genetics and Microbiology, Co-Director of the Center for MicroEngineered Materials, and a member of the Cancer Center at The University of New Mexico. He is one of four Fellows at Sandia National Laboratories, and a Distinguished Affiliate Scientist at the Sandia/Los Alamos National Laboratories Center for Integrated Nanotechnologies. His research focus is on processing, characterization, and understanding of porous and composite nanostructured materials and the development of novel functional bio/nano interfaces for applications in environmental microbiology and drug delivery. Brinker has co-organized over a dozen MRS symposia, where he introduced the interdisciplinary idea of "Better Ceramics through Chemistry," and co-chaired the 1990 MRS Spring Meeting

\section{Matthew Copel (2018)}

Copel is a research staff member at the IBM TJ Watson Research Center. He earned his $\mathrm{PhD}$ degree in physics from the University of Pennsylvania in 1986, where he studied the structure of metal surfaces. He has made contributions to areas where electronic materials are critical to industrial applications, using expertise in structural characterization to guide development. He co-invented the technique of surfactant mediated epitaxy. He currently serves on the Penn State Materials Research Institute Industrial Advisory Board. $\mathrm{He}$ is a Fellow of the American Physical Society. He has served on the MRS New Publications Products Subcommittee (2011-2014) and has participated in several MRS task forces.

\section{Paul S. Drzaic (2018)}

Drzaic is senior manager for emerging display technology for Apple, Inc., where he and his group are responsible for the evaluation, development, and implementation of new display technologies. A common research and development theme across Drzaic's career has been flexible displays and electronics and novel electro-optical effects. He was awarded the MRS Woody Award in 2009. He served as a volume organizer for MRS Bulletin in 2004 and has served as chair of $M R S$ Bulletin's Editorial Board since 2005. He was a symposium organizer for the first MRS symposium on flexible electronics in 2002 and served as a chair for the 2006 MRS Spring Meeting.

\section{Yury Gogotsi (2018)}

Gogotsi is a distinguished university professor and trustee chair in the Department of Materials Science and Engineering at Drexel University. He also holds courtesy appointments in the Departments of Chemistry and Mechanical Engineering and Mechanics at Drexel University. He is 
the founding director of the A.J. Drexel Nanomaterials Institute. His current research interests focus on chemistry of nanostructured carbons and carbides. He was a part of the team that discovered a new family of 2D carbides, nitrides, and carbonitrides of transition metals (MXenes). He has been active in MRS for more than 20 years. He has organized various MRS symposia, delivered numerous invited talks, and was selected for the Fred Kavli Distinguished Lectureship in Nanotechnology in 2014. He was the founding advisor of the MRS Student Chapter at Drexel and served as chair of the MRS Student Chapters Subcommittee from 2011 to 2015.

\section{Hideo Hosono (2016)}

Hosono is a professor in the Frontier Research Center and Materials and Structures Laboratory at the Tokyo Institute of Technology, and is a founding director of the Materials Research Center for Element Strategy. His research focuses on electroactive functionalities in transparent oxides. For MRS, he has been both an organizer and an invited speaker for various symposia.

\section{Young-Chang Joo (2018)}

Joo is a professor in the Department of Materials Science and Engineering at Seoul National University in South Korea since 1999. His recent research focuses on developing new pathways for synthesis of materials for energy devices based on nanoscale metallurgy. He has been involved in MRS since his graduate studies and has organized three symposia at MRS Meetings. He served as a Meeting chair for the 2008 MRS Fall Meeting and is a member of the MRS Program Development Subcommittee's tutorial review group.

\section{Karen L. Kavanagh (2017)}

Kavanagh is a professor of physics and an associate member of the Department of Chemistry and School of Engineering Science at Simon Fraser University. She also directs the 4D Labs Nanoimaging Facility. Her research is focused on atomic interfaces and nanostructures, with recent interest in nanocontacts, spin transport at electrodeposited metal-semiconductor interfaces, dislocations in nanowire heterostructures, mag-netic measurements using electron holography, fibbed nanohole arrays, and two-dimensional materials. She has served on the MRS Membership Committee in 1993 and has co-chaired multiple MRS symposia.

\section{Kornelius Nielsch (2016)}

Nielsch is the director of the Institute for Metallic Materials at the Leibniz Institute for Solid State and Materials Research Dresden. His research focuses on thermoelectric materials, topological insulators, and magnetic nanostructures. He has been a co-organizer of MRS symposia, a co-chair of the 2011 MRS Spring Meeting, and he served on the Program Development Subcommittee.

\section{Christine Ortiz (2017)}

Ortiz is the Morris Cohen Professor of Materials Science and Engineering and the Dean for Graduate Education at the Massachusetts Institute of Technology. Her research program focuses on the multiscale mechanics of musculoskeletal and exoskeletal structural biological materials, with the primary goal being to quantify and understand new mechanisms, phenomena, and design principles and how they determine function, quality, and pathology. Ortiz has been an active member of MRS throughout her professional career.

\section{Sabrina Sartori (2017)}

Sartori is an associate professor in the Physics Department at the University of Oslo, Norway. She is also the coordinator of the Energy and Environment Group at the University Graduate Center at Kjeller. Her research interests cover the synthesis and characterization of materials for hydrogen storage and batteries, with a particular focus on nanoscale and porous materials investigated with small-angle neutron and x-ray scattering, in situ synchrotron radiation, and powder neutron diffraction. In her academic role, she is engaged in the science and technology of materials for renewable energy. She is a member of the $M R S$ Bulletin Energy Quarterly Board.

\section{Magaly Spector (2018)}

Spector serves as the assistant to the president for strategic initiatives and professor in practice at The University of Texas at Dallas. She received her MS degree in electrical engineering in 1985 and her PhD degree in physics in 1993. She has pioneered a large number of new technologies and holds eight patents. In 2004, she was selected a Bell Labs Fellow for her contributions in solid-state physics, II-V material for semiconductor lasers, GaAs, integrated circuits, and quality and reliability of products used in high-speed optical transport systems for next-generation high bandwidth communication. She received the MRS Woody Award in 2013. She is the Diversity Subcommittee chair for MRS

\section{Loucas Tsakalakos (2016)}

Tsakalakos is currently the manager of the Photonics Laboratory at the General Electric-Global Research Center in Niskayuna, N.Y. His research focuses on the integration of heterogeneous thin-film and nanostructured materials systems for micro- and nano-device applications, as well as on the characterization of materials. For MRS, he has co-organized several symposia and served as a co-chair of the 2013 MRS Fall Meeting.

\section{Anke Weidenkaff (2017)}

Weidenkaff has been a full professor and chair for Materials Chemistry at the University of Stuttgart, Germany, since 2013. Her research interests comprise the development, synthesis, and characterization of advanced thermoelectric materials (perovskitetype oxides and oxynitrides, half-Heusler compounds, and carbon nanotube composite materials) for an efficient energy conversion. She has organized several MRS symposia and is an editorial board member of the MRS Bulletin and MRS Bulletin Energy Quarterly. She has been a member of the E-MRS Executive Committee since 2012, and served as one of the E-MRS Spring Meeting chairs in 2013. 